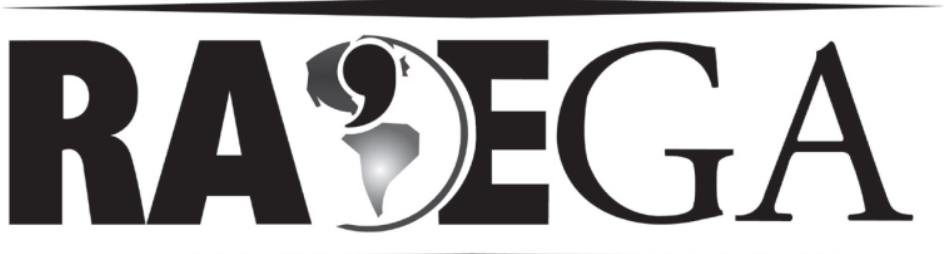

O ESPAÇO GEOGRÁFICO EM ANÁLISE

\title{
CAVERNA DAS MÃOS, RURÓPOLIS, PARÁ: IMPORTANTE EXEMPLO BRASILEIRO DE ARTE RUPESTRE EM ZONA AFÓTICA
}

\section{CAVERNA DAS MÃOS, RURÓPOLIS, PARÁ: IMPOTANT BRAZILIAN EXAMPLE OF DARK ZONE CAVE ART}

\author{
Luiz Eduardo Panisset Travassos ${ }^{1}$ \\ Bruno Durão Rodrigues ${ }^{2}$ \\ Aécio Rodrigo Schwertz Motta ${ }^{3}$
}

\section{RESUMO}

O município de Rurópolis, no sudoeste paraense, compõe uma região rica em cavernas areníticas, bem como registros rupestres únicos até então. Por esse motivo, o presente trabalho tem por objetivo registrar as pinturas rupestres mais importantes da região no tocante à zona de iluminação da caverna. Os autores apresentam uma descrição geral da caverna das Mãos, após visitas de campo e análise de mapas geológico, geomorfológico e de vegetação, propondo uma primeira aproximação sobre os registros rupestres encontrados. Destaca-se que tais cavernas já eram conhecidas por alguns moradores da região, mas somente a partir de 2010 foram cadastradas no Cadastro Nacional de Cavernas (CNC) da Sociedade Brasileira de Espeleologia (SBE). Destacase, ainda, que os autores do presente artigo são, antes de tudo, espeleólogos e geógrafos, fato que os limitam a apresentar propostas mais profundas além da identificação e descrição preliminar dos sítios para futuros estudos.

Palavras-chave: pinturas rupestres; cavernas areníticas; caverna das Mãos; Rurópolis; Pará.

\footnotetext{
${ }^{1}$ Geógrafo, Professor do Programa de Pós-Graduação em Geografia da PUC Minas. luizepanisset@gmail.com

${ }^{2}$ Geógrafo, Doutorando em Geografia pelo Programa de Pós-Graduação em Geografia da PUC Minas. brunodurao@terra.com.br

${ }^{3}$ Especialista em Gestão e Educação Ambiental pela ESEA/TO, Membro da Sociedade Brasileira de Espeleologia(SBE 1703). rodrigosmotta@hotmail.comL
} 


\section{ABSTRACT}

The municipality of Ruropólis, southwestern Pará, comprises a region rich in sandstone caves and unique rock art records so far. Therefore, this study aims to confirm the most important representations of dark zone rock art from the region through pictures and a general description of the cave. With field visits and analysis of geologic, geomorphologic and vegetation maps, it was possible to characterize the environment in which the cave is located and propose a first approximation regarding its rock panels. It worth mentioning that these caves were known by some local residents, but only after 2010 they were registered in the Cadastro Nacional de Cavernas (CNC) of the Brazilian Speleological Society (SBE). It should also be noted that the authors of this paper are, first of all, cavers and geographers, which didn't make in depth analysis regarding the rock art, but a preliminary identification and description of the sites for future studies.

Key-words: rock art; sandstone caves; cavernas das Mãos; Rurópolis; Pará.

\section{INTRODUÇÃO}

Para Travassos, Rodrigues e Motta (2012), a região da Amazônia Legal brasileira é alvo de pesquisas das mais diversas que vão desde os estudos de solo, geologia, geomorfologia, biogeografia até produtos de origem florestal. Salvo os estudos referentes às cavernas em formações ferríferas de Carajás (PA) e os estudos das cavidades em quartzito dos Tepuis venezuelanos, pouco se tem divulgado sobre o trabalho realizado por espeleólogos em cavidades carbonáticas e areníticas da região

Por esse motivo, o presente trabalho tem por objetivo registrar, mais especificamente a caverna das Mãos (PA-329) na região norte do país. Para isso, durante a observação in situ, procedeu-se com o registro digital dos paineis completos, bem como dos motivos individualmente. Dessa forma, posteriormente, será possível realizar decalques ou cópias digitais das pinturas conforme proposto por Aguiar e Oliveira (2010).

Travassos, Rodrigues e Motta (2012), ao descrever 6 cavernas com expressivos registros rupestres, atribuem à caverna das Mãos valor especial. Muitas das cavernas da região de Rurópolis já eram conhecidas pelos moradores, principalmente por causa da dedicação da Sra. Erismar de Souza 
Silva que há décadas tem visitado tais locais. A partir de 2011, tais descobertas passaram a ser sistematicamente registradas por Motta, sócio da Sociedade Brasileira de Espeleologia.

No município de Rurópolis cerca de seis cavernas contam com expressivos registros rupestres. Destaca-se, porém, a "descoberta" recente de outras cavidades com arte rupestre e que ainda não foram registradas por Travassos, Rodrigues e Motta (2012), nem neste artigo. Aqui, optou-se por registrar a caverna das Mãos pelo fato de se destacar no cenário regional.

As missões de campo tiveram como objetivo principal a identificação e registro dos grafismos e pinturas rupestres feitas em seis cavernas areníticas, a saber: caverna Jatobá (PA-326), caverna das Mãos (PA-329), caverna Borboleta Azul (PA-332), caverna Fernanda Caroline (caverna do 110/PA-336), caverna Caximbão (PA-431) e caverna das Damas (PA-466). Neste artigo somente a caverna das Mãos foi identificada, visto que outro trabalho sobre o conjunto das seis cavidades e sua inserção na geologia regional havia sido submetido a outro periódico e foi publicado em 2012 (TRAVASSOS; RODRIGUES; MOTTA, 2012) .

Mesmo tendo em vista o estudo exploratório das cavernas, é possível concluir que os sítios visitados possuem características diferentes das registradas por Pereira (2003) sendo, a princípio, únicos na região. Destaque deve ser dado justamente à caverna das Mãos por apresentar pinturas rupestres que foram realizadas na zona afótica da caverna, fato raro, senão único no Brasil. As demais cavernas que se tem notícia apresentam a arte rupestre em zona disfótica ou de penumbra, fato que também merece destaque conforme afirmam Travassos, Rodrigues e Motta (2012).

\section{Área de estudos}

As cavernas estão localizadas dentro dos limites do município de Rurópolis no estado do Pará. De acordo com Vasquez, Sousa e Carvalho (2008), a geologia regional é representada por rochas paleozóicas recobertas por densas áreas de floresta amazônica. Em escala local, de maneira geral, a região das cavernas apresenta arenitos, folhelhos e siltitos. $\mathrm{O}$ acesso à região 
de estudos se dá a partir de Belém em direção à Santarém e, por fim à Itaituba, por via aérea, terrestre ou fluvial. Inserida na bacia hidrográfica do Amazonas, a principal drenagem regional é o rio Tapajós, afluente da margem direita do rio Amazonas. Partindo de Itaituba, o acesso às cavidades é feito por via rodoviária pela Transamazônica e, obviamente, por trechos feitos a pé.

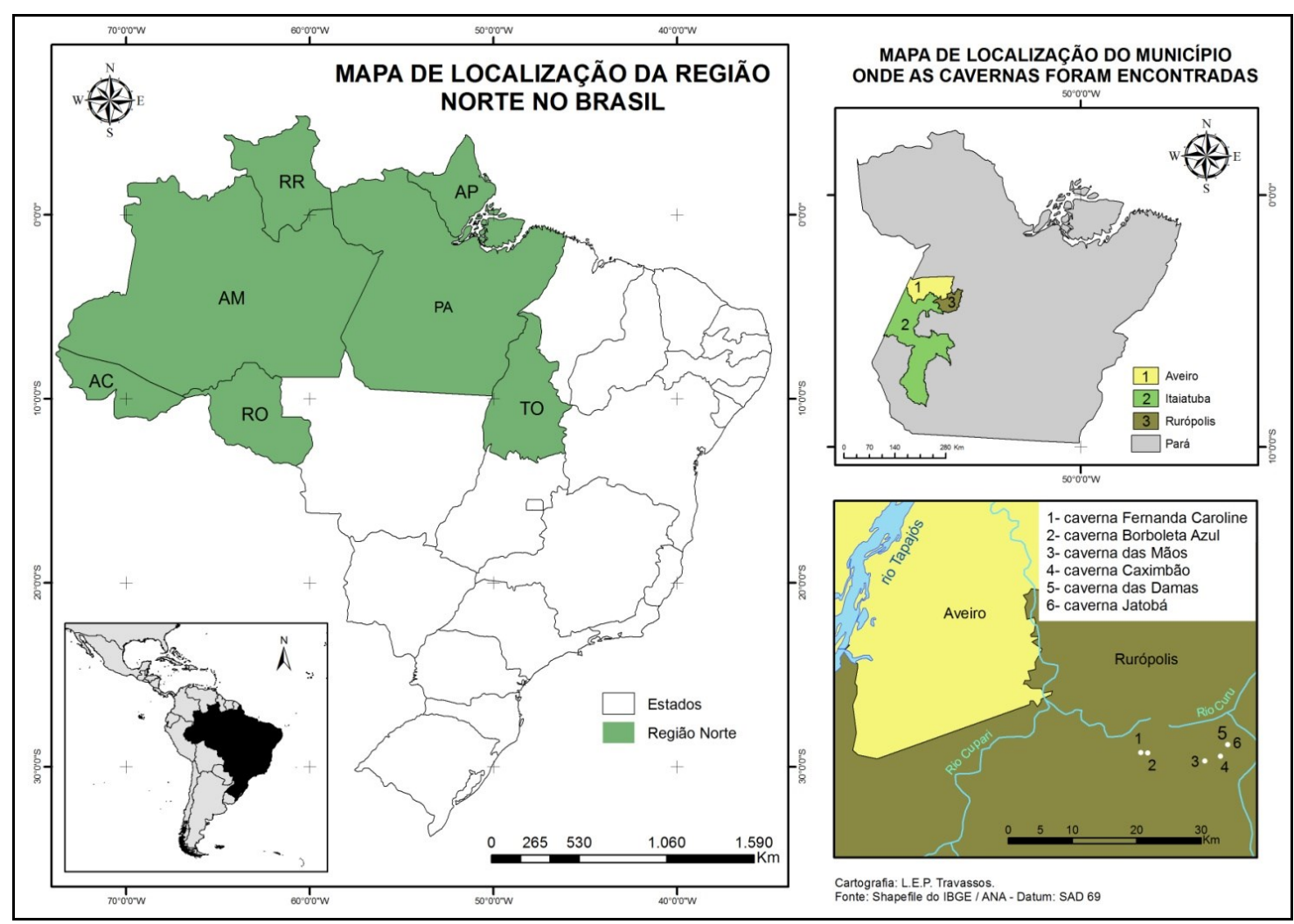

Figura 1 - Mapa de localização das cavernas e da área de estudos (TRAVASSOS; RODRIGUES; MOTTA, 2012).

\section{Geologia simplificada da região}

A área sobre a qual as cavernas estão inseridas destaca-se que são compostas pelas rochas elaboradas a partir da deposição sedimentar. Em linhas gerais, segundo Vasquez, Souza e Carvalho (2008), a região é recoberta por rochas sedimentares formadas entre o período Devoniano ao Cretáceo (416 a 65 milhões de anos) e com a gênese atrelada a processos flúviolacustrinos, flúvio-deltáicos, flúvio-eólicos e a ambientes marinhos, glaciais, de planícies de maré e flúvio-deltáicos. As ocorrências litológicas mais comuns são os arenitos, folhelhos, siltitos, lentes de calcário, evaporitos, pelitos e conglomerados. A este pacote sedimentar estão atrelados os Grupos Urupadi 
(D2e e D2mi), Curuá (D3c1c), Tapajós (C2i e C2 no) e Javari (K2E1 ac). Merecem destaque os folhelhos, siltitos e arenitos do Grupo Urupadi, originários de processos sedimentares flúvio-deltáicos (VASQUEZ; SOUZA; CARVALHO, 2008) e que tem como Formações significativas a Ererê (D2e) e a Maecuru, esta última com o Membro Lontra (D2ml) onde as cavernas do presente estudo estão localizadas. Por fim, depósitos aluvionares (N4a) holocênicos estão localizados às margens do rio Tapajós e também na base das ilhas fluviais deste rio, entre os municípios de Itaituba e Aveiro (Figura 2).

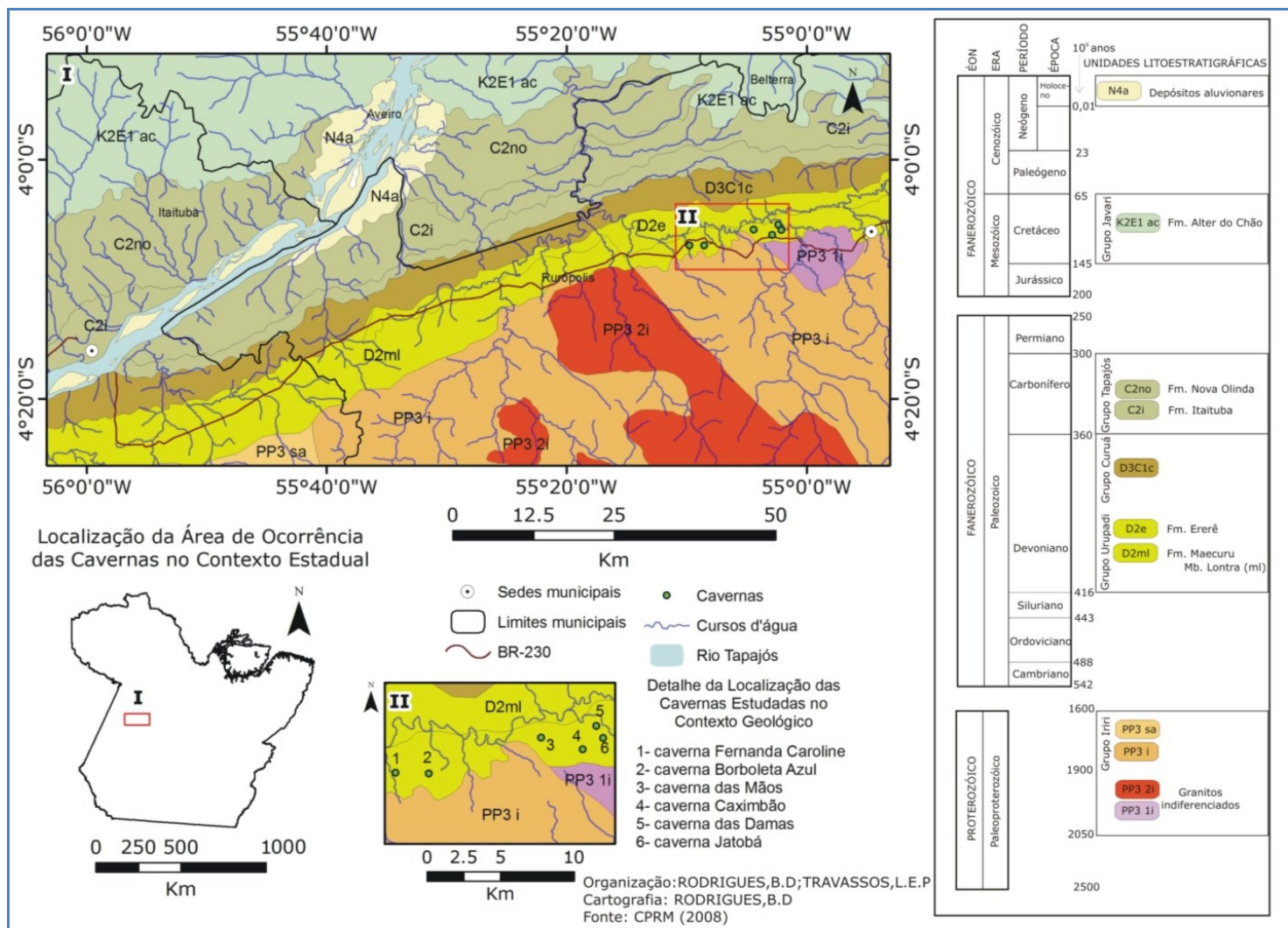

Figura 2 - Mapa geológico da área de estudos com a localização das cavernas pesquisadas (TRAVASSOS; RODRIGUES; MOTTA, 2012, p. 9).

\section{Geomorfologia, fitogeografia e usos da terra}

De acordo com os dados do projeto RADAM (1975), Folha Tapajós SB21 a região de ocorrência das cavernas areníticas está sob o domínio morfoclimático dos Planaltos Amazônicos Rebaixados, na subunidade dos Planaltos Rebaixados do Médio Amazonas. As formas dominantes são caracterizadas por colinas dissecadas de topo aplainado resultantes de 
processos de pediplanação pleistocência (VENTURA; D'ÁVILA; BARBOSA, 1975, p.134), conforme observado na figura 3.

As formas derivadas da geomorfologia são recobertas pelas formações da Floresta Tropical Densa, também, sinonimicamente denominada Floresta Ombrófila Densa (TERESO et al., 1975, p.307). A Floresta Ombrófila Densa da região de ocorrência das cavidades, segundo Nimer (1979), está inserida no domínio climático Tropical Quente do subdomínio úmido com um período seco anual variando de 2 a 3 meses. As temperaturas médias anuais são superiores a $20^{\circ} \mathrm{C}$ e precipitação anual em torno de $1754 \mathrm{~mm}$ na sede do município de Itaituba (TERESO et al., 1975, p.320-321).

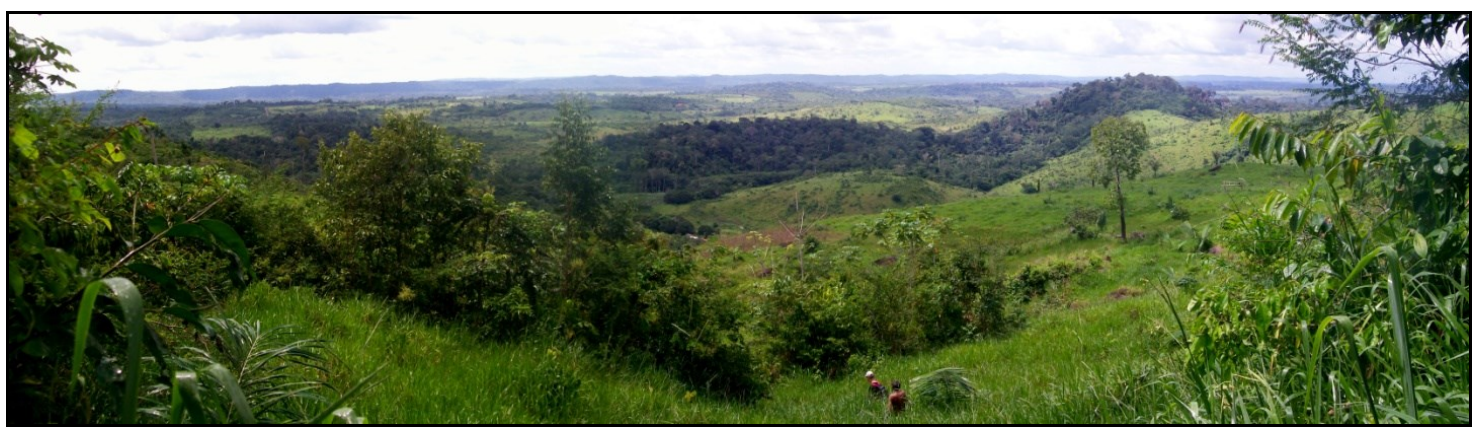

Figura 3- Colinas dissecadas de topo aplainado (Foto: Bruno Durão Rodrigues, 2012)

No domínio da Floresta Ombrófila Densa e em especial da região de ocorrência das cavidades, ocorrem variações ecossistêmicas definidas por Tereso et al. (1975) como as Florestas Ombrófilas Submontana que são caracterizadas por possuírem uma cobertura florestal baixa (se comparadas a outras variações ecossistêmicas) com o dossel variando de 10 a 25 metros de altura (TERESO et al.,1975,p.306).

Com relação aos usos da terra, as Florestas Ombrófilas Submontanas vêm cedendo espaços à pecuária extensiva (figura 4) e também ao extrativismo vegetal, principalmente nas áreas das baixas vertentes. As altas e médias vertentes, de maneira geral, ainda se encontram preservadas; locais estes de ocorrência das cavidades. 


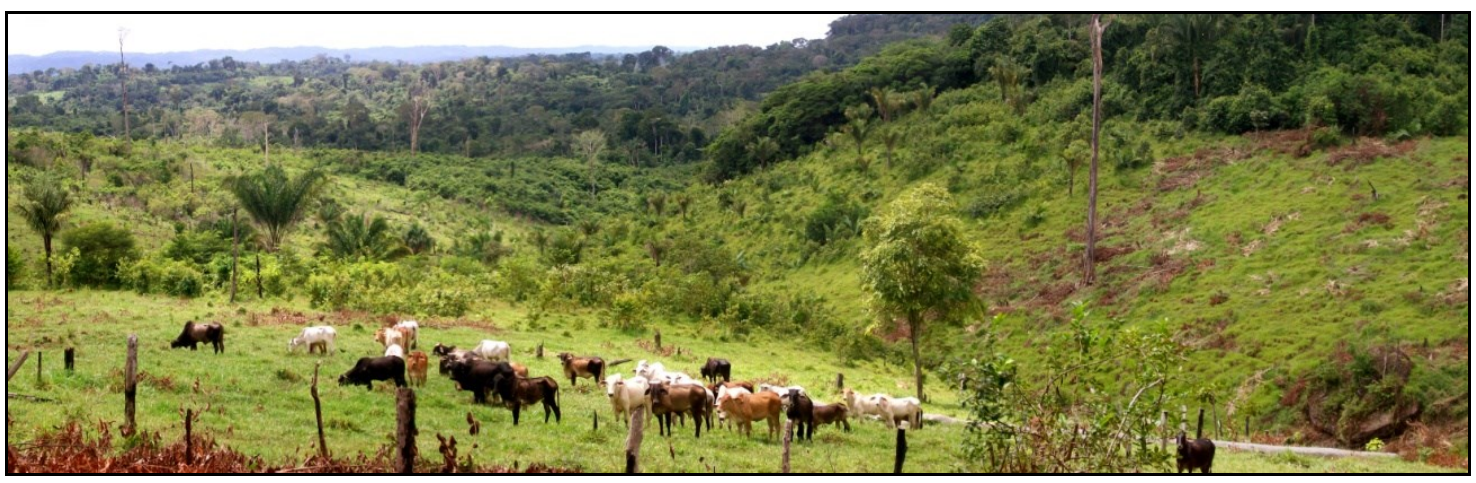

Figura 4- Pecuária extensiva nas áreas de Floresta Ombrófila Submontana (Foto: Bruno Durão Rodrigues, 2012)

\section{As cavernas, gravuras e pinturas rupestres}

Desde os primórdios do aparecimento do Homem na Terra, ao longo da história da humanidade, as cavernas desempenharam um importante papel na principalmente no tocante à proteção contra as intempéries. Ao se abrigarem em tais espaços, muitos grupos humanos deixavam registros de sua ocupação na forma de vestígios arqueológicos como material lítico, cinzas de fogueiras, ossos, pinturas e grafismos (TRAVASSOS; RODRIGUES; MOTTA, 2012).

Para Bahn (2004a) embora a maior parte da arte rupestre pré-histórica ocorra em abrigos rochosos pouco profundos e iluminados, é possível afirmar que também existem importantes conjuntos em diversos países que foram encontrados em zonas afóticas, no interior das cavernas. O autor cita várias cavernas encontradas na Europa e que apresentam pinturas datadas da Era do Gelo da Eurásia. Na Noruega, por exemplo, pinturas foram encontradas no interior de diversas cavernas e foram datadas em cerca de 3.000 anos atrás.

Tal fenômeno não é exclusivo da Europa e uma série de cavernas da Austrália, Tasmânia, Nova Guiné, Borneo, China e América do Norte apresentam uma profusão de arte rupestre dentro das cavidades e não somente na zona eufótica e disfótica. Greer e Greer (1998) afirmam que existem mais de 31 sítios com arte rupestre na zona afótica na América do Norte, 22 no México e mais de 100 em Cuba, entre outros países. Os autores também afirmam que alguns painéis, mesmo que sejam iluminados pela luz das claraboias, somente são encontrados após o percurso por condutos em 
zona afótica com o uso de luz artificial. Stone (1995) registrou inúmeros exemplos de arte rupestre em zona afótico em Yucatan (México), Guatemala e sul do Belize atribuindo a tais registros significado sagrado (TRAVASSOS; RODRIGUES; MOTTA, 2012).

Devido ao fato das cavernas serem consideradas por muitas culturas como lugares misteriosos e ameaçadores, o público em geral atribui caráter mágico, esotérico, secreto e ritualístico à arte rupestre (BAHN, 2004a). Observa-se na literatura que muitos destes registros foram realizados em sítios mais "abertos" como os abrigos sob rocha ou paredes com incidência constante de luz. Por esse motivo, acredita-se que pinturas feitas na escuridão total das cavernas devem ser consideradas mais "importantes", pois, nas palavras de Bahn (2004a), foram feitas de forma mais privada. Além disso, Travassos, Rodrigues e Motta (2012) destacam o fato de ter sido necessária a geração de iluminação artificial por meio do uso do fogo, por exemplo. Faulkner (1997) destaca a Crumps Cave com glifos realizados em sedimentos argilosos (mudglyphs) a cerca de 1.000 metros da entrada.

Amplamente divulgado na literatura internacional é o fato de que os Maias utilizavam as cavernas para rituais que muitas vezes eram realizados após longas jornadas em direção ao seu interior. Dessa forma, Bahn (2004a) afirma que escuridão total, o silêncio, a perda do senso de direção, as mudanças de temperatura e as sensações claustrofóbicas poderiam ser os principais motivos que levavam o homem primitivo ao interior destes espaços para se expressarem ou realizarem seus rituais.

De acordo com Bednarik (2004a), o estudo da arte rupestre nas cavernas europeias é tido como oficialmente iniciado em 1879 com a descoberta da arte paleolítica de Altamira, Espanha. A partir de então, outros estudos passaram a ser realizados. Entretanto, sabe-se que o registro de sua existência não é recente. Em 1458, o Papa Calisto III, havia decretado que as cerimônias religiosas realizadas na "caverna espanhola com pinturas de cavalos" teriam que acabar. Portanto, tais pinturas já eram conhecidas na Idade Média, ainda que não de forma cientíica. Bahn (2004b) afirma que, na Europa, muitas pinturas foram encontradas em locais menos "públicos" 
denotando uma motivação "religiosa" para sua execução por estarem ligadas a uma complexa mitologia e, portanto, uma única explicação não é possível para decifrá-las e compreendê-las (TRAVASSOS; RODRIGUES; MOTTA, 2012).

Em relação à profundidade com que as pinturas foram feitas na America do Sul, Stone (2004) afirma que os exemplos mais antigos ocorrem em abrigos sob rocha areníticas de 10 a 20 metros e nenhum dos registros da literatura dão conta de pinturas na zona afótica ou totalmente escura das cavernas até o momento. Até mesmo a Cueva de las Manos, na Patagônia argentina, possui suas pinturas de cerca de 7.000 anos feitas em zona iluminada pela luz natural. Ainda para Stone (2004), em relação às Américas, somente na América do Norte (Tennessee e Kentucky) foram encontradas pinturas rupestres de 1.600 a 1.000 anos localizadas na zona afótica. Os conjuntos rupestres foram feitos na lama ou sedimento das paredes, bem como na forma de incisões na rocha, assim como nos abrigos e cavernas pesquisadas no Pará por Pereira (2003; 2006) e aquelas registradas por Travassos, Rodrigues e Motta (2012).

Um importante registro de pinturas rupestres em zona de penumbra no Brasil foi feito por Leite (1990; 1992). Destaca-se que em seu estudo a autora afirma que no "painel VIII" as figuras só podem ser visualizadas com clareza quando "uma luz forte incide sobre elas" (LEITE, 1992, p.433-434). Em outro caso, no Pará, Pereira (2003, p. 148) afirma que o mesmo ocorre na gruta do Pilão localizada em Monte Alegre que, mesmo com a necessidade de iluminação artificial para identificar as pinturas, o local não é totalmente escuro. Assim sendo, tais exemplos nos levam a crer que tais grafismos não foram feitos em zona totalmente escura ou afótica como os que foram identificados na caverna das Mãos a centenas de metros da entrada.

\section{A caverna das Mãos}

Conforme destacado na introdução, sabe-se que as cavernas do Pará são desenvolvidas em formações ferríferas, em carbonatos, quartzitos e em arenitos. Até o momento, somente as cavernas areníticas do baixo Tapajós apresentaram pinturas, incisões e grafismos executados na rocha, perfazendo um significativo conjunto rupestre. 
A caverna das Mãos recebe seu nome, obviamente, pelas "mãos" impressas em suas paredes. Localizada no Km-120 da rodovia Transamazônica, sentido Itaituba/Rurópolis é, talvez, a caverna mais importante do município. Sob as coordenadas 0409'23"S e 5504'19"W desenvolve-se por cerca de 800 metros nos arenitos da Formação Maecuru, Membro Lontra (D2ml).

Possui duas entradas: uma principal e outra secundária a partir de um abatimento. Na entrada secundária é possível identificar dois paineis com gravuras rupestres, um em frente ao outro, e ambos em zona disfótica (penumbra). Não possuem o mesmo estilo ou tradição e, portanto, é possível inferir que tenham sido feitos em períodos diferentes de ocupação da caverna. O painel das gravuras apresenta grande profusão de zoomorfos que podem ser relacionados a imagens de aves, répteis, peixes e até mesmo um mamífero, talvez um peixe-boi (Figuras 5 e 6 ).

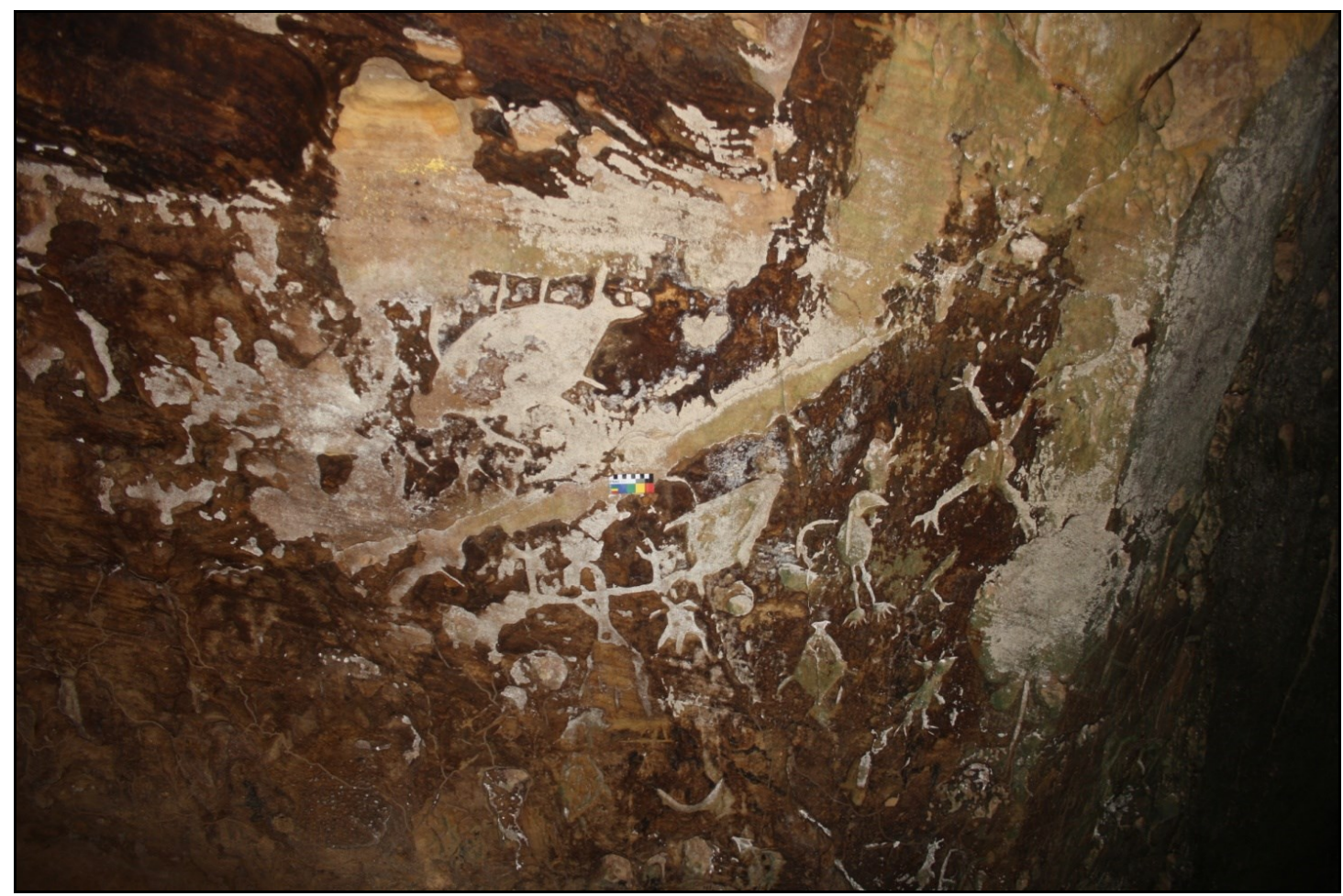

Figura 5 - Aspecto geral do primeiro painel da segunda entrada da cavernas das Mãos. A escala da IFRAO no centro da foto possui $10 \mathrm{~cm}$ (Foto: Luiz E. P. Travassos, 2012) 


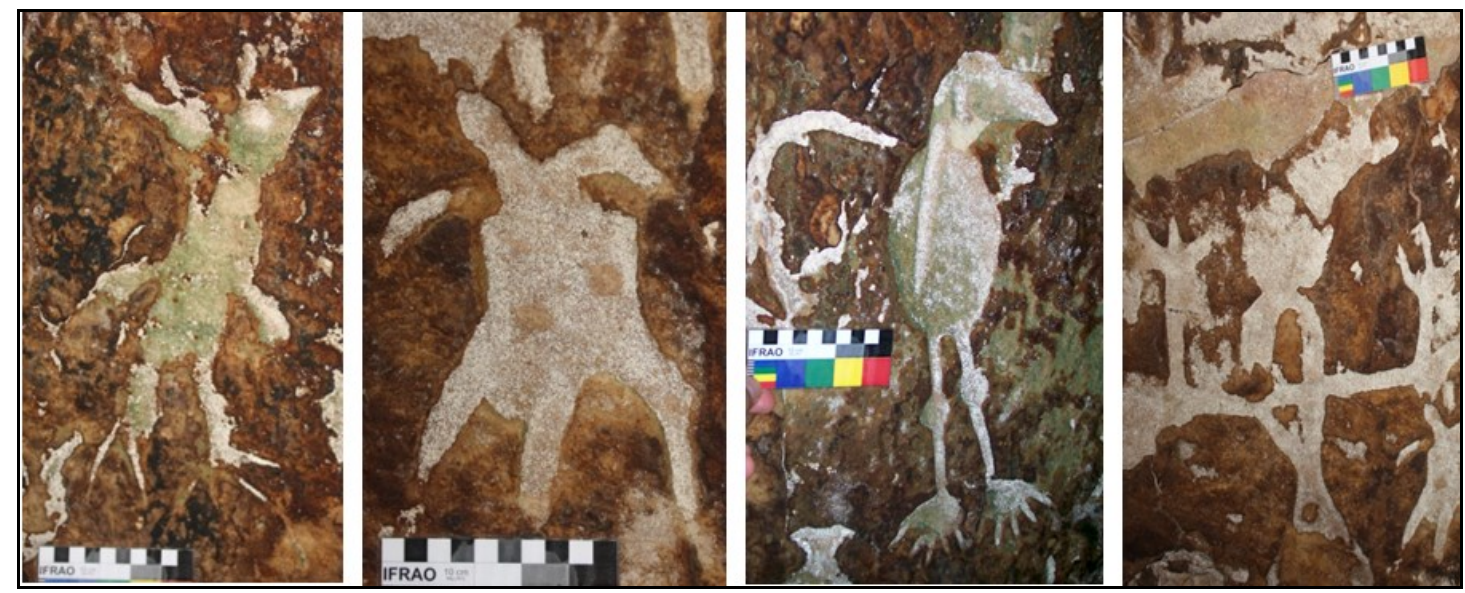

Figura 6 - Detalhe de algumas das imagens do painel da figura 3 (Foto: Bruno Durão Rodrigues e Luiz E.P. Travassos, 2012).

Pela outra entrada da caverna, seguindo um curso d'água por cerca de 350 metros, é possível identificar os conjuntos de pinturas rupestres com as mãos em positivo nas paredes. A importância da caverna, além de sua própria geologia e todo o conjunto rupestre em si, é aumentada pelo fato das pinturas terem sido feitas na zona afótica, totalmente sem incidência de luz natural. Infere-se que para sua realização, o indivíduo ou grupo que as pintou deveria dominar o fogo e saber manejá-lo até o interior (TRAVASSOS; RODRIGUES; MOTTA, 2012). Por vezes, o caminho até os paineis se dá por condutos meandrantes, bem como por seções de teto baixo (Figuras 7, 8 e 9). 


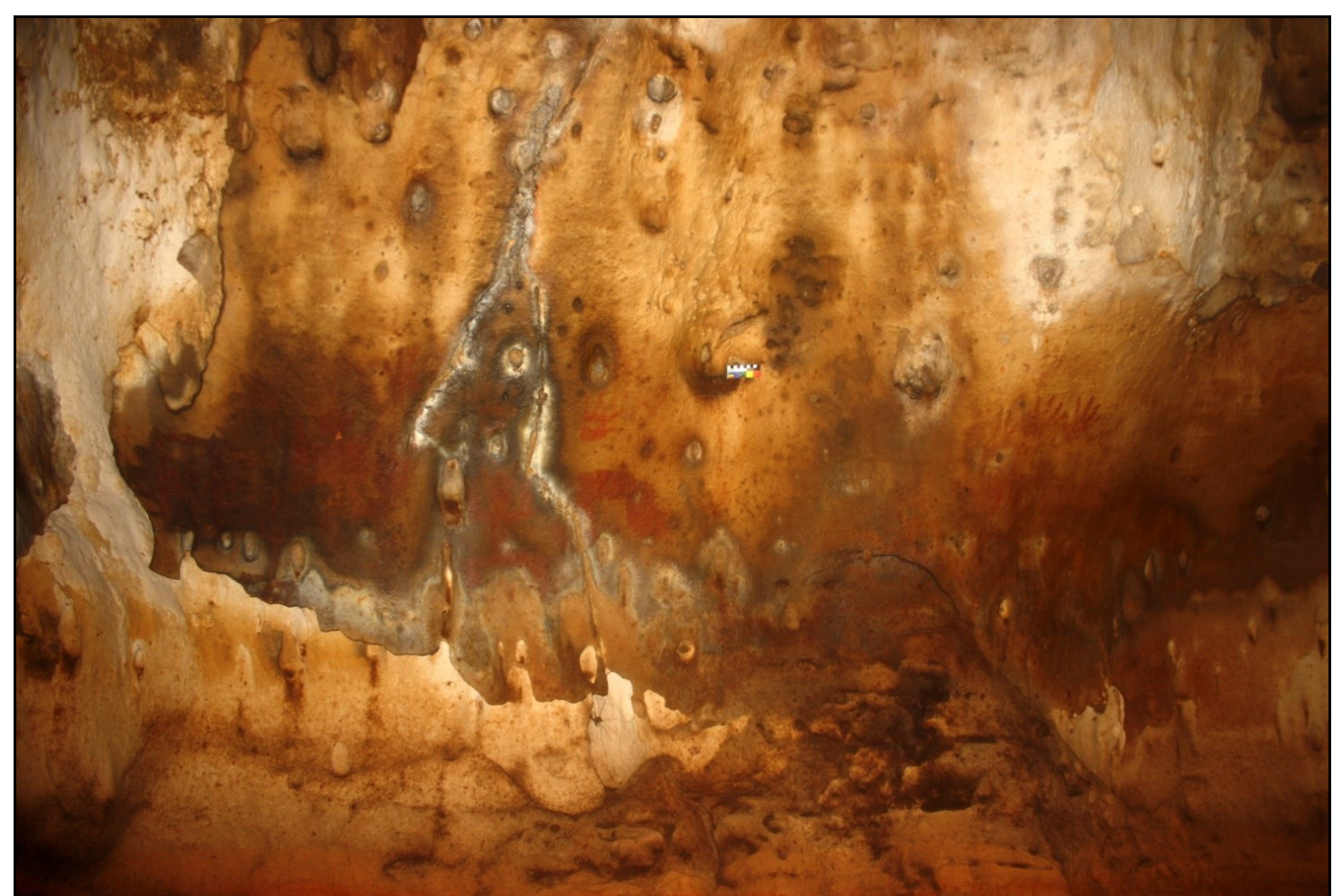

Figura 7 - Primeiro painel. Apresenta concreções ou espeleotemas sobre as pinturas. Da esquerda para a direita é possível identificar figuras geométricas, um antropomorfo e as mãos em positivo. A escala da IFRAO no centro da imagem possui $10 \mathrm{~cm}$.

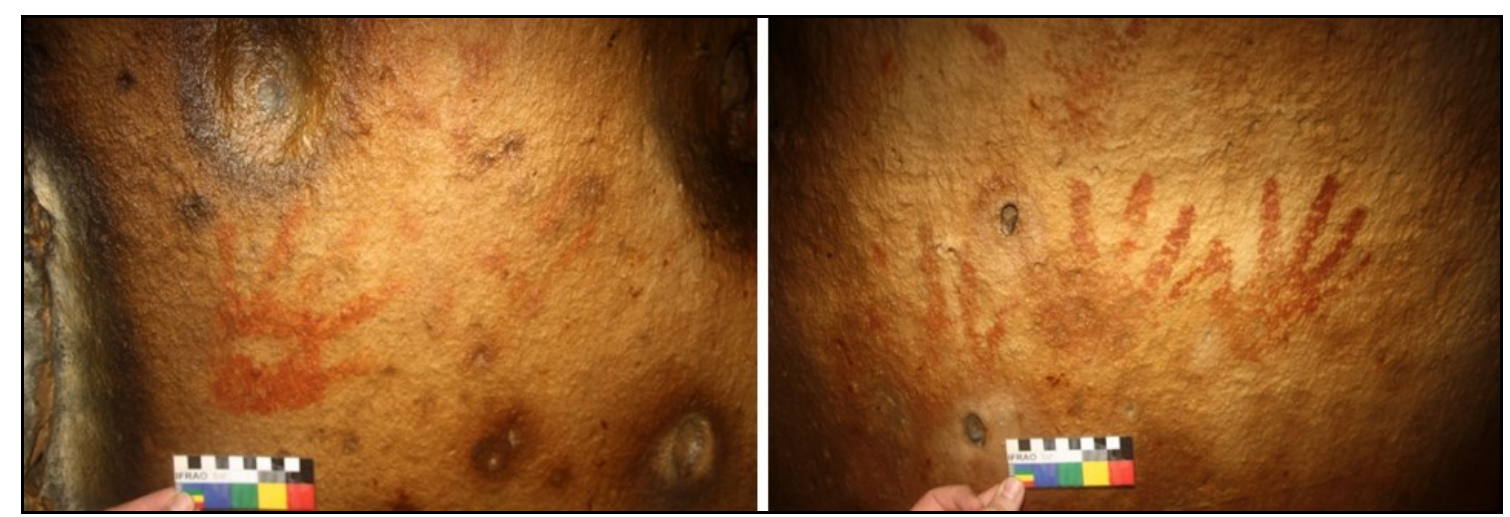

Figura 8 - Detalhe das mãos em positivo do primeiro painel (Foto: Luiz E.P. Travassos, 2012). 


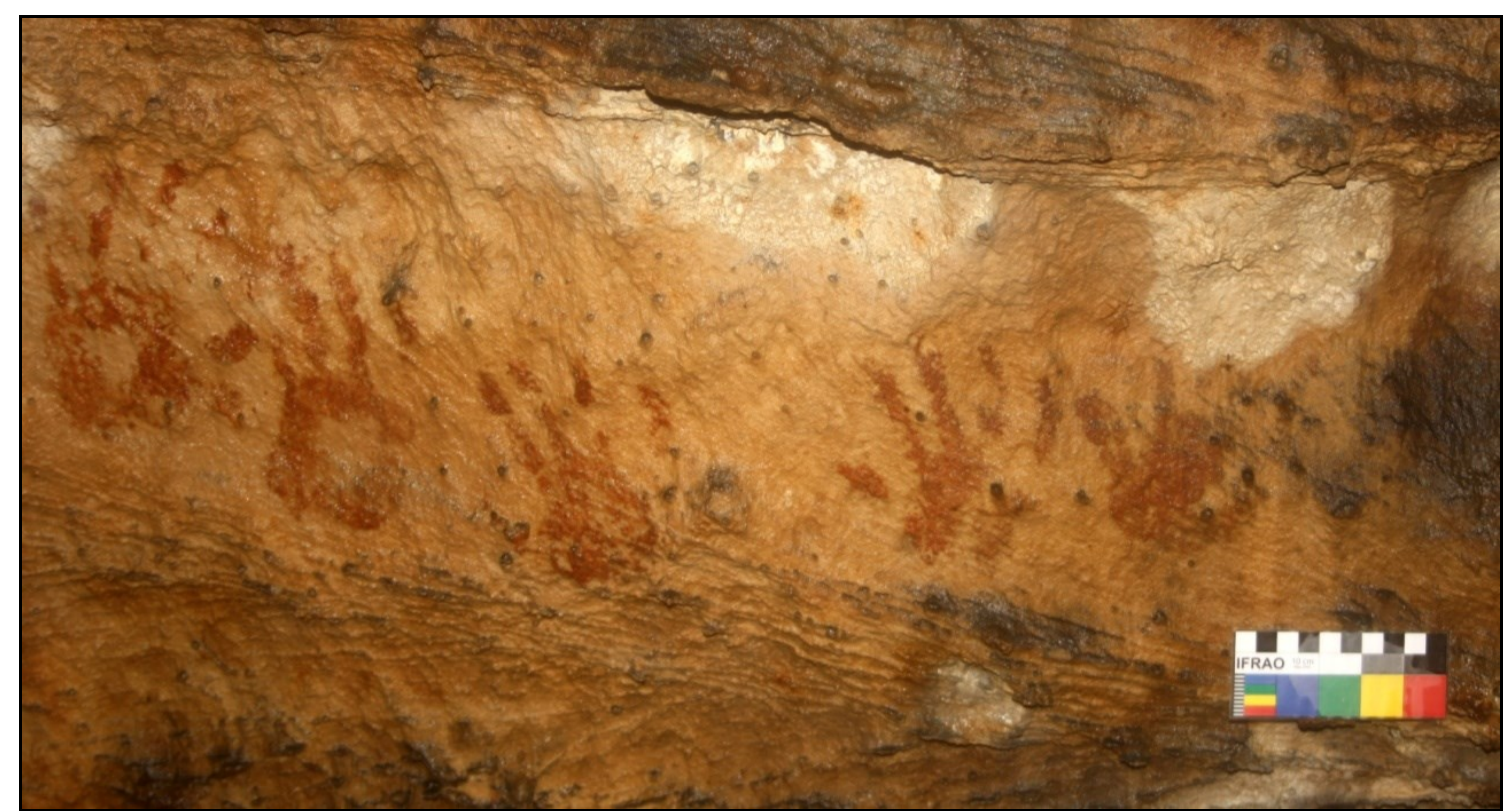

Figura 9 - Detalhe das mãos em positivo do segundo painel. Para chegar a esse painel é preciso passar por um pequeno trecho de teto baixo de cerca de $90 \mathrm{~cm}$. As pinturas estão a cerca de $90 \mathrm{~cm}$ do chão. (Foto: Luiz E.P. Travassos, 2012).

Tal configuração vai de encontro ao que Greer e Greer (1999; 2002) afirmam ser comuns ao se estudar a arte rupestre em zona afótica. A dificuldade de acesso para se chegar ao lugar do ritual é considerado necessário para esses tipos de sítios. Em algumas cavernas com registro de arte rupestre em zona afótica também é possível identificar pegadas que foram preservadas sobre os sedimentos argilosos. Cerca de 274 pegadas bem preservadas foram registradas por Toner (2009) na caverna do Jaguar, na região centro-norte do Tennessee, Estados Unidos. No caso da caverna das Mãos, em Rurópolis, tal fato é extremamente difícil de ocorrer devido a presença do curso d'água subterrâneo.

\section{Considerações finais}

O presente trabalho buscou demonstrar que a área compreendida entre o rio Tapajós e o rio Xingu, de Itaituba a Altamira, surge no cenário espeleológico e arqueológico da Amazônia como uma região propícia para novas descobertas e pesquisas sistemáticas. As outras pinturas rupestres que foram identificadas e registradas em Travassos, Rodrigues e Motta (2012) e 
neste trabalho precisam ser estudadas em seu conjunto. Antes de se tentar estabelecer precisamente quais comunidades ou grupos ocupavam as cavernas da região, é preciso estudar detalhadamente os sítios, fato que deve ocorrer a partir destas breves descrições.

Com os dados obtidos neste estudo preliminar é possível afirmar que a caverna das Mãos é o exemplo mais singular até então encontrado na região. Seu caráter ritualístico não pode ser negado e outros exemplos similares ainda podem ser encontrados na vasta região amazônica, bem como no Brasil.

Destaca-se que as posições de "primeiro" ou "segundo" painel adotadas neste trabalho dependem do ponto de vista adotado, uma vez que não se sabe ainda qual dos painéis teria sido feito inicialmente e foram classificados apenas de acordo com sua localização na caverna. Não se sabe se o painel identificado pela figura 9 teria sido o segundo a ser usado marcando o "fim" da caverna ou se a existência do trecho de rastejo ou "teto-baixo" teria sido demarcado como o ponto mais "sacrificante" da caverna e, portanto, ideal para o início dos possíveis rituais.

De acordo com Faulkner (1997) existe uma verdade universal em relação ao estudo da pré-história e que as teorias sobre o desenvolvimento cultural estão constantemente sendo revisados a partir do momento em que arqueólogos descobrem novas evidências sobre o passado.

Assim sendo, destaca-se que os autores do presente artigo são, antes de tudo, espeleólogos e geógrafos, fato que os limitam a apresentar propostas mais profundas além da identificação e descrição preliminar dos sítios para futuros estudos que devem ser realizados.

\section{Referências}

AGUIAR, R. L. S.; OLIVEIRA, J. E. O Uso da Reprodução Digital no Registro e Catalogação de Figuras de Arte Rupestre em Situações de Impacto e Alto Risco. Diálogos. DHI/PPH/UEM, p.239-244, 2010.

BAHN, P.G. Art in caves. In: GUNN, John (ed.). Encyclopedia of Caves and Karst Science. New York/London: Fitzroy Dearborn, 2004a. p. 83- 84. 
BAHN, P.G. Art: Cave art in Europe. In: GUNN, John (ed.). Encyclopedia of Caves and Karst Science. New York/London: Fitzroy Dearborn, 2004b. p. 9091.

BEDNARIK, R. Art in caves: History. In: GUNN, John (ed.). Encyclopedia of Caves and Karst Science. New York/London: Fitzroy Dearborn, 2004a. p.85.

BEDNARIK, R. Art: Cave art in Australasia. In: GUNN, John (ed.). Encyclopedia of Caves and Karst Science. New York/London: Fitzroy Dearborn, 2004b. p.8890.

FAULKNER, C. H. Four thousand years of native american cave art in the southern Appalachians. Journal of Cave and Karst Studies, v. 59, n. 3, p.148153, 1997.

GREER, J.; GREER, M. Dark Zone Pictographs at Surratt Cave, Central New Mexico. In: WISEMAN, R. N.; O'Laughlin, T. C.; SNOW, C. T.. Forward Into the Past: Papers in Honor of Teddy Lou and Francis Stickney. The Archaeological Society of New Mexico, v. 28, Archeological Society of New Mexico, Albuquerque, 2002. p. 37-46.

GREER, J.; GREER, M. Dark zone and twilight zone pictugraphs in U-Bar Cave, Southwestern New Mexico. In: HEDGES, K. Rock art paper, Volume 14. San Diego Museums Papers 36, 1999. p. 11-19.

GREER, J.; GREER, M. Dark zone rock art in North America. In: HEDGES, K. Rock art paper, Volume 13. San Diego Museums Papers 35, 1998. p. 135-143.

LEITE, N. Arte rupestre na gruta do Índio (MG-JF 17). In: CONGRESSO DA ABEQUA, 3, 1992. Anais... Belo Horizonte: ABEQUA, 1992. p. 431-457.

LEITE, N. O estudo sistemático dos grafismos da Gruta do Índio (JanuáriaMG.) no contexto arqueológico regional. 248 f. 1990. Tese Doutorado. USP.

NIMER,E. Climatologia do Brasil.Rio de Janeiro: IBGE,SUPREN, 1979, 421p.

PEREIRA, E. Arte rupestre na Amazônia: Pará. Belém/São Paulo: Museu Paraense Emílio Goeldi/UNESP, 2003. 245p.

PEREIRA, E. S. Historia de la investigación sobre el arte rupestre en la Amazonía brasileña. Revista de Arqueologia Americana, v. 24, p. 67-98, 2006.

STONE, A. Art: Cave art in the Americas. In: GUNN, John (ed.). Encyclopedia of Caves and Karst Science. New York/London: Fitzroy Dearborn, 2004. p.9193.

STONE, A. J. Imagens from the underground: Naj Tunich and the Tradition of Maya Cave Painting. Austin: University of Texas Press, 1995. 
TERESO, E. F. M.; GÓES FILHO, L.; FERREIRA, H. C.;VELOSO, H. P., FONSECA,W. N. SILVA,S.B. As Regiões Fitoecológicas, sua Natureza e seus Recursos Econômicos - Estudo Fitogeográfico. In: PROJETO RADAM - Folha SB-21 Tapajós. Rio de Janeiro: DNPM - Departamento Nacional de Produção Mineral, 1975. p.287-384.

TRAVASSOS, L.E.P.; RODRIGUES, B.D.; MOTTA, A. R. S. Representações rupestres em cavernas areníticas de Rurópolis, Pará: uma primeira aproximação. Olam: Ciência \& Tecnologia (Rio Claro. Online), v.12, n.1-2, p. 532, 2012.

TONER, M. Ancient Cavers. American Archaeology, v. 13, n.3, p.12-18, 2009.

VASQUEZ, M.L.; SOUZA, C.S.; CARVALHO, J.M.A. (Orgs.). Mapa Geológico e de Recursos Minerais do Estado do Pará. 2008. Escala 1:1.000.000. Programa Geologia do Brasil (PGB), INtegração, atualização e Difusão de Dados da Geologia do Brasil. Mapas Geológicos Estaduais. CPRM- Serviço Geológico do Brasil. Superintendência Regional de Belém.

VENTURA,L.M.; D’ÁVILA,L.M.; BARBOSA,G.V. Geomorfologia. In: PROJETO RADAM - Folha SB-21 Tapajós. Rio de Janeiro: DNPM - Departamento Nacional de Produção Mineral, 1975. p.117-158. 